\title{
Patient Safety Culture and Leadership in Canada's Academic Health Sciences Centres
}

\section{Rationale}

Over the past few years, the focus on patient safety has emerged as an important policy issues on the national health policy agenda, both nationally and internationally. Given the importance of this issue, and the shared commitment to continuing to improve patient safety, the Academy of Canadian Executive Nurses (ACEN) and the Association of Canadian Academic Healthcare Organizations (ACAHO) have developed a joint policy statement on patient safety cultures and leadership within Canada's Academic Health Sciences Centres.

\section{Background to Patient Safety as a Health Policy Issue}

Pressures to improve patient safety within our healthcare system are continuing to gain momentum (Nicklin et al. 2004). Concerns of both the public, providers and institutions are reinforced by the release of key reports including findings from the Adverse Events study in Canada that indicated 36.9\% of adverse events were preventable (Baker et al., 2004). Another study found that close to two-thirds of adverse events were preventable (Leape et al. 2001).

The incidence of adverse events (AEs) in acute care hospitals has been reported in the USA (Brennan et al., 1991; Kohn, Corrigan and Donaldson, 1999; Thomas et al., 2000), Australia (Wilson et al. 1995), Britain (Vincent, Neale and Woloshynowych 2001), New Zealand (Davis et al. 2002) and Denmark (Schiøler et al. 2001). These studies indicate that between 5 percent and 20 percent of patients admitted to hospital experience AEs, of which roughly $50 \%$ are preventable, and that AEs cost healthcare systems billions of dollars in additional hospital stays.

There is evidence to suggest that some errors can be prevented. Errors are the result of the complicated interface between providers and technology, providers and the system; and the complex interaction among the many different healthcare providers (Turnball 2001). Collectively, these reports describe the outcomes associated with errors and adverse events in the healthcare delivery and the urgency of addressing systems issues.

\section{Canada's Response to Patient Safety}

Canada's response to growing concern about healthcare safety is evident by several national, provincial and territorial and local patient safety initiatives including research activities, coalitions, committee work, and national reports that have called attention to the current gaps in safety in the healthcare system.
In 2002, the National Steering Committee on Patient Safety released its report (NSCPS 2002) and the Canadian Council on Health Services Accreditation embedded patient safety in its accreditation standards for healthcare organizations (CCHSA 2003). In December 2003, the federal government announced the creation of the Canadian Patient Safety Institute (CPSI) and the Health Council of Canada. It is important to note that key messages coming from these national initiatives include focusing on systemic challenges, building a culture of patient safety, stronger accountability mechanisms, and quality improvement throughout our healthcare system.

\section{Academic Health Sciences Centres: Leaders in Innovation and Excellence in Patient Care, Research and Education}

Given the critical role that Academic Health Sciences Centres (AHSCs) play as centres of health innovation, and providers a quality training environment for most of Canada's healthcare professionals, leadership for patient safety must emanate from these institutions.

AHSCs have an established track record in providing stateof-the art healthcare, (e.g., developing, assessing and applying the most up-to-date diagnostic and treatment modalities for all complexities of illness) and, as such, are well positioned to champion patient safety initiatives by working with and advising key stakeholders (i.e., governments, professional associations and others) with regard to patient safety in academic healthcare settings and within our national healthcare system (Institute of Medicine 2003; Nicklin et al. 2004).

Research that is fundamental to advancing patient safety currently originates from AHSC's. AHSCs are "hub" organizations where service delivery is the platform for the education of future healthcare providers and where the development of new knowledge and innovation through research occurs. AHSCs are where care is provided to the most acutely ill and ethnically, culturally diverse patient populations.

Due to the multiple mandates, AHSCs are highly complex environments and are potentially more vulnerable to near miss and adverse events (Baker et al. 2004; Ebright and Rapala 2003; NSCPS 2002). Learning that occurs in AHSC environments, including the production of knowledge related to quality care and accountability mechanisms, risk and risk reduction, commonly becomes the foundation for the establishment of new standards for the delivery of safe, quality healthcare throughout the country (Nicklin et al. 2004).

A joint policy statement of the Academy of Canadian Executive Nurses and the Association of Canadian Academic Healthcare Organizations. We wish to thank Lianne Jeffs RN, MSc, for her writing assistance. 


\section{ACEN/ACAHO Recommendations for Leadership in Developing Stronger Safety Cultures in Academic Health Science Centres}

Our accountability as learning organizations (Carroll and Edmondson 2002) includes working collaboratively with our Board of Directors; members of multi-disciplinary healthcare teams; healthcare consumers (i.e., patients, family members, close friends, the general public, etc.); and external partners including academic institutions, all levels of government and national and provincial and territorial accreditation bodies (e.g., Canadian Council on Health Services Accreditation) in identifying risk situations, developing strategies to reduce these risks and creating environments that improve patient safety practices.

In specific terms, ACEN and ACAHO recommend the following two overarching strategies, with key components, to strengthen leadership and patient safety cultures in AHSCs:

1. More cohesive alignment of organizational vision, processes and structures in AHSCs for patient safety cultures is integral to ensuring the design and delivery of safe, quality patient care. Key components of this strategy include:

- Create a strategic orientation focused on a culture of safety and quality improvement that identifies safety as a system property, grounded in patient safety principles (Institute of Medicine, 2003; Institute of Medicine 2001; Kohn, Corrigan and Donaldson 1999) throughout the entire organization.

- Balance benchmarks in operational efficiency with quality/safety professional practices (Firth-Cozens 2004).

- Develop and implement open and transparent disclosure policies (e.g. adverse event and near miss reporting) in practice (NSCPS 2002).

- Involve patients as partners in care (Institute of Medicine 2001; Kohn, Corrigan and Donaldson 1999; NSCPS 2002).

- Establish and sustain quality work environments with effective health human resource practices and evidence-based practice and decision-making (clinical, administrative, educational, etc.) that support the provision of quality healthcare (Aiken, Clarke and Sloane, 2001; Baumann et al., 2001; Institute of Medicine 2003; NSCPS 2002).

- Develop and/or strengthen initiatives designed to enhance collaboration among all members of the care delivery team (Baker et al. 2004, NSCPS 2002).

- Pilot and evaluate innovative approaches to the delivery of healthcare (Nicklin et al. 2004).

- Evaluate organizational performance in achieving a patient safety culture in accreditation, hospital report cards, etc.

2. Strengthen partnerships with affiliated academic partners, professional and institutional associations, clinical practitioners and all levels of government to lead innovation in design and delivery of safe quality care. Key components of this strategy include:
- Cultivate stronger linkages between AHSCs and affiliated academic institutions to ensure that patient safety is integral to curriculum development, faculty development, clinical placements/rotations and research (Nicklin et al. 2004).

- Refine and develop national patient safety accountability mechanisms and indicators with CCHSA and other interested organizations (CCHSA 2003; Nicklin et al. 2004, NSCPS 2002)

- Support other national patient safety initiatives including the Canadian Patient Safety Institute and the Health Council of Canada (both provincial/territorial and national (Nicklin et al. 2004).

As leaders within AHSCs, ACEN and ACAHO will continue to lead the cultural change that will ensure the adoption of safe, effective patient care delivery systems. Our collaborative mandates include the ongoing development and implementation of strategies designed to provide quality healthcare; encourage and facilitate research into safety cultures and systematic practices; and educate future healthcare professionals and other personnel in AHSCs. There may be an opportunity to build ongoing curriculum for both professional and organizational development around patient safety cultures and practices. Together, these actions will foster the necessary learning, professional development and change to continue to advocate a patient safety culture in AHSCs that will serve as a benchmark learning organization to all healthcare organizations in Canada.

ACEN and ACAHO continue their collaborative efforts on leadership and patient safety cultures within AHSCs by focusing on patient safety at upcoming joint meetings. From this joint dialogue, strategic directions and accountability mechanisms will be identified. In this context, we encourage feedback and suggestions in response to this joint policy statement.

\section{References:}

Aiken, L.H, S.P. Clarke and D.M. Sloane. 2001. "Hospital Restructuring: Does It Adversely Affect Care and Outcomes?" Journal of Health and Human Services Administration 23 (40): 416-42.

Baker, G.R, P.G. Norton, V. Flintoft, R. Balis, A. Brown, J. Cox, E. Etchells, W. Ghali,, P. Hebert, S. Majumdar, M. O'Beirne, L. palaciosDerflingher, R. Reid, S. Sheps, and R. Tamblyn. 2004. "The Canadian Adverse Event Study: The Incidence of Adverse Events Among Hospitalized Patients in Canada." Canadian Medical Association Journal 170 (11): 1678-86.

Baumann, A., L. O'Brien-Pallas, M. Armstrong-Stassen, J. Blythe, R. Bourbonnais, S. Cameron, D. Irvine Doran, M. Kerr, L. McGillis Hall, M. Zina, M. Butt, and L. Ryan. 2001. "Commitment and Care: The benefits of a healthy workplace for nurses, their patients and the system." Report submitted to the Canadian Health Services Research Foundation, Ottawa ON. Retrieved June 1, 2004.

< http://www.chsrf.ca/docs/finalrpts/pscomcare_e.pdf>

Brennan, T.A. L.L. Leape, M. Nan, et al. 1991. “Incidence of Adverse Events and Negligence in Hospitalized Patients: Results of the Harvard Medical Practice Study I." New England Journal of Medicine 324: 370376. 
Canadian Council on Health Services Accreditation. 2003. CCHSA and Patient Safety. Ottawa: Canadian Council on Health Services Accreditation. Retrieved February 7, 2004. <http://www.cchsa.ca> Canadian Nursing Advisory Committee. 2002. Our Health, Our future Creating Quality Workplaces for Canadian Nurses. Final report of the Canadian Nursing Advisory Committee. Retrieved June 1, 2004. <http://www.hc-sc.gc.ca>

Carroll, J.S. and A.C. Edmondson. 2002. "Leading Organizational Learning in Health Care." Quality and Safety in Health Care 11: 51-56.

Davis, P., R. Lay-Yee, R. Briant, W. Ali, S. Scott and S. Schug. 2002. "Adverse Events in New Zealand Public Hospitals I: Occurrence and Impact." New Zealand Medical Journal 115(1167): U271.

Ebright, P and K. Rapala. 2003. "Tools and Systems for Improved Outcomes-Do You Know It When You See It? Outcomes Management 7(3): 91-93.

Firth-Cozens, C. 2004. "Organizational Trust: The Keystone to Patient Safety." Quality and Safety in Healthcare 13: 56-61.

Institute of Medicine. 2003. Academic Health Centres: Leading Change in the 21st Century. Washington, DC: National Academy Press. Retrieved July 2, 2004. <www.iom.edu>

Institute of Medicine. 2003. Keeping Patients Safe: Transforming the Work Environment of Nurses. Washington, DC: National Academy Press. Retrieved July 2, 2004. <www.iom.edu>

Institute of Medicine. 2001. Crossing the Quality Chasm: A New Health System for the 21st Century. Washington, DC: National Academy Press. Retrieved July 2, 2004. <www.iom.edu>

Kohn, L.T., J.M. Corrigan and M.S. Donaldson, (eds). 1999. To Err Is Human: Building Safer Health System. Washington, DC: National Academy Press.

Leape, L. L., T.A., Brennan, N. Laaird, A.G. Lawthers, A.R. Logalio, B.A. Barnes, et al. 1991. "The Nature of Adverse Events in Hospitalized Patients." New England Journal of Medicine 324 (6): 377-384.

National Steering Committee on Patient Safety. 2002. Building a Safer System: A National Integrated Strategy for Improving Patient Safety in Canadian Health Care. Ottawa: National Steering Committee on Patient Safety. Retrieved August 2, 2004. <http://www.longwoods.com/special/patientsafety.html>

Nicklin, W., H. Mass, D.D. Affonso, P. O'Connor, M. Ferguson-Paré, L. Jeffs, D. Tregunno and P. White. 2004. "Patient Safety Culture and Leadership Within Canada's Academic Health Science Centres: Towards the Development of a Collaborative Position Paper." Canadian Journal of Nursing Leadership 17(120): 22-34.

Schiøler, T., H. Lipczak, P.B. Lilja, B. Pedersen, S. Torben, K. Mogensen, B. Bech, A. Stockmarr, A. Rud Svenning and A. Frølich. 2001. "Incidence of Adverse Events in Hospitals. A Retrospective Study of Medical Records." Ugeskr Laeger 163(39): 5370-8.

Thomas, E.J., D.M. Studdert, H.R. Burstin, et al. 2000. "Incidence and Types of Adverse Events and Negligent Care in Utah and Colorado." Medical Care 38 (3):261 -71.

Turnball, J. E. 2001. “All Components of the System Must Be Aligned." Healthcare Papers 2(1):38-43.

Vincent, C., G. Neale and M. Woloshynowych. 2001. "Adverse Events in British Hospitals: Preliminary Retrospective Record Review." British Medical Journal 322(7285): 517-519.

Wilson, R.L, W.B., Runciman, R.W. Gibberd et al. 1995. "The Quality in Australian Health Care Study." Medical Journal of Australia 163: 458-471.

\section{About the Associations}

The Association of Canadian Academic Healthcare Organizations (ACAHO) is a member-based association that represents more than 40 teaching centres - which are a combination of Teaching Hospitals and Regional Health Authorities who have jurisdictional responsibilities for the academic mission (i.e., service provision, teaching and education, and supporting and conducting health research). Members range from single hospital organizations to multisite, multi-dimensional regional facilities."

The Academy of Canadian Executive Nurses (ACEN) is a national organization of nurse executives from academic health science centers, and the deans/ directors of schools of nursing within Canada. ACEN's purpose is to provide a national voice and forum for executive nurse leaders within academic healthcare environments and university nursing facilities to contribute to the health of Canadians and the advancement of Nursing.

Recruit from our readers - leaders in nursing, IT and administration - more than 155,000 readers every month

For a comprehensive recruiting strategy contact Susan Hale at shale@longwoods.com

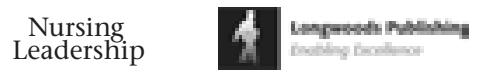

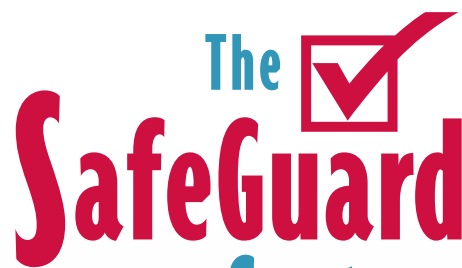

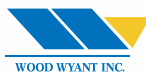

For more info visit us at www.woodwyant.com or call 1.800.361.7691.

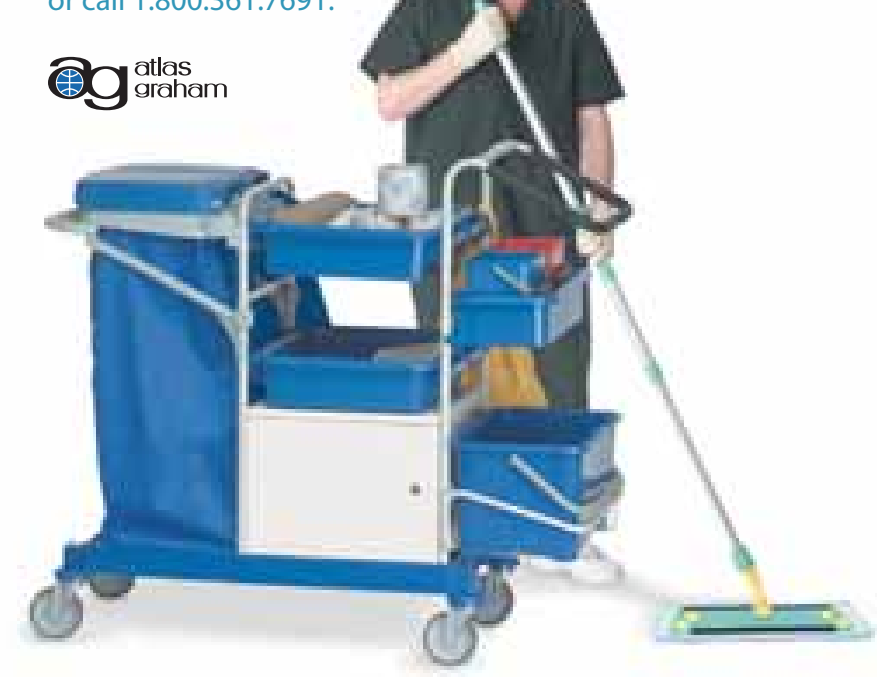

